\title{
From satellite altimetry to Argo and operational oceanography: three revolutions in oceanography
}

\author{
P. Y. Le Traon* \\ Ifremer and Mercator Ocean, 8-10 rue Hermès - Parc Technologique du Canal, 31520 Ramonville, St. Agne, France \\ * Invited contribution by P. Y. Le Traon, recipient of the EGU Fridtjof Nansen Medal 2012.
}

Correspondence to: P. Y. Le Traon (pierre.yves.le.traon@ifremer.fr)

Received: 5 April 2013 - Published in Ocean Sci. Discuss.: 18 July 2013

Revised: 25 September 2013 - Accepted: 25 September 2013 - Published: 29 October 2013

\begin{abstract}
The launch of the French/US mission Topex/Poseidon (T/P) (CNES/NASA) in August 1992 was the start of a revolution in oceanography. For the first time, a very precise altimeter system optimized for largescale sea level and ocean circulation observations was flying. $\mathrm{T} / \mathrm{P}$ alone could not observe the mesoscale circulation. In the 1990s, the ESA satellites ERS-1/2 were flying simultaneously with T/P. Together with my CLS colleagues, we demonstrated that we could use $\mathrm{T} / \mathrm{P}$ as a reference mission for ERS-1/2 and bring the ERS-1/2 data to an accuracy level comparable to T/P. Near-real-time high-resolution global sea level anomaly maps were then derived. These maps have been operationally produced as part of the SSALTO/DUACS system for the last $15 \mathrm{yr}$. They are now widely used by the oceanographic community and have contributed to a much better understanding and recognition of the role and importance of mesoscale dynamics. Altimetry needs to be complemented with global in situ observations. At the end of the 90s, a major international initiative was launched to develop Argo, the global array of profiling floats. This has been an outstanding success. Argo floats now provide the most important in situ observations to monitor and understand the role of the ocean on the earth climate and for operational oceanography. This is a second revolution in oceanography. The unique capability of satellite altimetry to observe the global ocean in near-real-time at high resolution and the development of Argo were essential for the development of global operational oceanography, the third revolution in oceanography. The Global Ocean Data Assimilation Experiment (GODAE) was instrumental in the development of the required capabilities. This paper provides an historical perspective on the development of these three revolutions
\end{abstract}

in oceanography which are very much interlinked. This is not an exhaustive review and I will mainly focus on the contributions we made together with many colleagues and friends.

\section{Introduction}

In the early 1990s, one century after the Nansen's Fram expedition, a small altimetry community was exploring the oceans with a new and wonderful instrument: the US/French mission Topex/Poseidon (T/P) (CNES/NASA). This has been an exciting era. For the first time, a very precise altimeter system optimized for large-scale sea level and ocean circulation observations was flying. T/P revolutionized our vision and understanding of the large-scale sea level and ocean circulation variations. In the 1990s, the ESA satellites ERS$1 / 2$ were flying simultaneously with T/P. The joint use of T/P and ERS-1/2 provided new views of the ocean circulation at high resolution; this also led to many discoveries, in particular, on mesoscale variability. Altimetry needs to be complemented by in situ observations and models. In the end of the 90s, a major international initiative was launched to develop Argo, the global array of profiling floats, as an initial joint venture between CLIVAR and the Global Ocean Data Assimilation Experiment (GODAE). Argo has been an outstanding success. The unique capability of satellite altimetry to observe the global ocean in near-real-time at high resolution and the development of Argo were essential to the development of global operational oceanography. GODAE (1998-2008) was phased with the T/P and ERS-1/2 successors (Jason-1 and ENVISAT) and was instrumental in the 
development of global ocean analysis and forecasting capabilities. The development of such an integrated approach (satellite and in situ observations, models) has been another great adventure and another series of major achievements in oceanography.

This paper will cover these three revolutions or breakthroughs in oceanography. This is not meant at all to be an exhaustive review. I will mainly try to summarize and illustrate the contributions we made together with many colleagues and friends. The main focus will be satellite altimetry. I will start with a brief overview of the development of satellite altimetry and, in particular, the T/P breakthrough of high precision altimetry. A summary of science investigations from satellite altimetry over the past $20 \mathrm{yr}$ will then be given. I will then cover the development of the SSALTO/DUACS products and illustrate the contribution they have made to a better recognition of the importance and role of mesoscale variability. The development of Argo and global operational oceanography will then be reviewed. Complementarities with satellite altimetry will be emphasized. A focus on European contributions, in particular, in the framework of the Euro-Argo research infrastructure and the GMES/Copernicus Marine Service will also be given. Lastly, lessons, perspectives and new challenges for the integrated global ocean observing system will be discussed.

\section{The development of satellite altimetry}

Satellite altimetry is one of the most important satellite techniques for oceanography. Over the past $20 \mathrm{yr}$, it has revolutionized our vision and understanding of ocean circulation. Satellite altimetry provides global, real time, all-weather sea surface heights measurements (SSH) (sea level) at high space and time resolution. Sea level is directly related to ocean circulation through the geostrophic approximation. Sea level is also directly related to the density structure of the ocean interior and is a strong constraint for inferring the 4-D ocean circulation through data assimilation. This explains the unique and fundamental role of satellite altimetry for data assimilation and operational oceanography.

\subsection{Principle of satellite altimetry}

The altimetry measurement principle is simple (although the system is complex). An altimeter is an active radar that sends a microwave pulse towards the ocean surface. A very precise on board clock measures the return time of the pulse from which the distance or range between the satellite and the sea surface is derived. The range precision is a few centimeters for a distance of 800 to $1300 \mathrm{~km}$. An altimeter mission generally includes a bi-frequency altimeter radar (usually in $\mathrm{Ku}$ and C or S Band) (for ionospheric corrections), a microwave radiometer (for water vapor correction) and a tracking system for precise orbit determination (Laser, GPS, Doris) that provides the orbit altitude relative to a given earth ellipsoid. The altimeter measures the distance between the satellite and the ocean surface. Using a precise orbitography system, the position of the satellite relative to a reference ellipsoid is determined. The combination of these two measurements yields the estimation of the sea level relative to a reference ellipsoid. This estimation comprises the geoid (an equipotential of the earth gravity field to which a motionless ocean would exactly conform) and the ocean dynamic topography. The geoid has variations of up to $100 \mathrm{~m}$ and the ocean dynamic topography (the parameter of interest here) has variations of up to $1 \mathrm{~m}$. For a comprehensive description of altimeter measurement principles, the reader is referred to Chelton et al. (2001).

Altimeter missions provide along-track measurements every $7 \mathrm{~km}$ along repetitive tracks (e.g. every 10 days for the TOPEX/Poseidon and Jason series and 35 days for ERS and ENVISAT). The distance between tracks is inversely proportional to the repeat time period (e.g. about $315 \mathrm{~km}$ at the equator for TOPEX/Poseidon and $90 \mathrm{~km}$ for ERS/ENVISAT). The satellite usually repeats over exactly the same ground track pattern every cycle; therefore, every cycle it observes the same geoid signal and the dynamic topography (which is time varying). This allows a precise estimation of the sea level or dynamic topography anomaly even if the geoid is not known. Thanks to the recent GRACE and GOCE gravimetric missions, the geoid is now known with a precision of a few centimeters for scales larger than $100 \mathrm{~km}$. This now allows estimating much more precise mean dynamic topography and thus absolute dynamic topography.

\subsection{Past, present and future altimeter missions}

Satellite altimetry is now a very mature technique. The concept was first demonstrated with GEOS-3 and Seasat in 1975 and 1978, respectively. GEOSAT ERM (Exact Repeat Mission) (1986-1989) can be considered as the actual start of the altimeter era. It was particularly suitable for mesoscale observations due to its long duration (almost $3 \mathrm{yr}$ ) and its 17 day repeat cycle. TOPEX/POSEIDON (T/P) (1992-2005) was, however, the major breakthrough for satellite altimetry. Due to its high accuracy, it has provided for the first time a precise description of global mean sea level, largescale sea level and ocean circulation variations. T/P was launched in 1992 and its follow-on missions Jason-1 and Jason-2 were launched in 2001 and 2008, respectively. ERS1 (1991-1996), ERS-2 (1995-2002) and ENVISAT (20022012) provided complementary sampling that is needed, in particular, for ocean mesoscale variability monitoring. They also provided high latitude coverage. Present and future missions for the next decade include Cryosat-2, HY-2, AltiKa (SARAL), Sentinel-3, Jason-3 and Jason CS. SWOT will be the demonstration of a new concept (interferometry and SAR) with new capabilities at very high resoution for mesoscale/submesoscale ocean observations over a swath. 


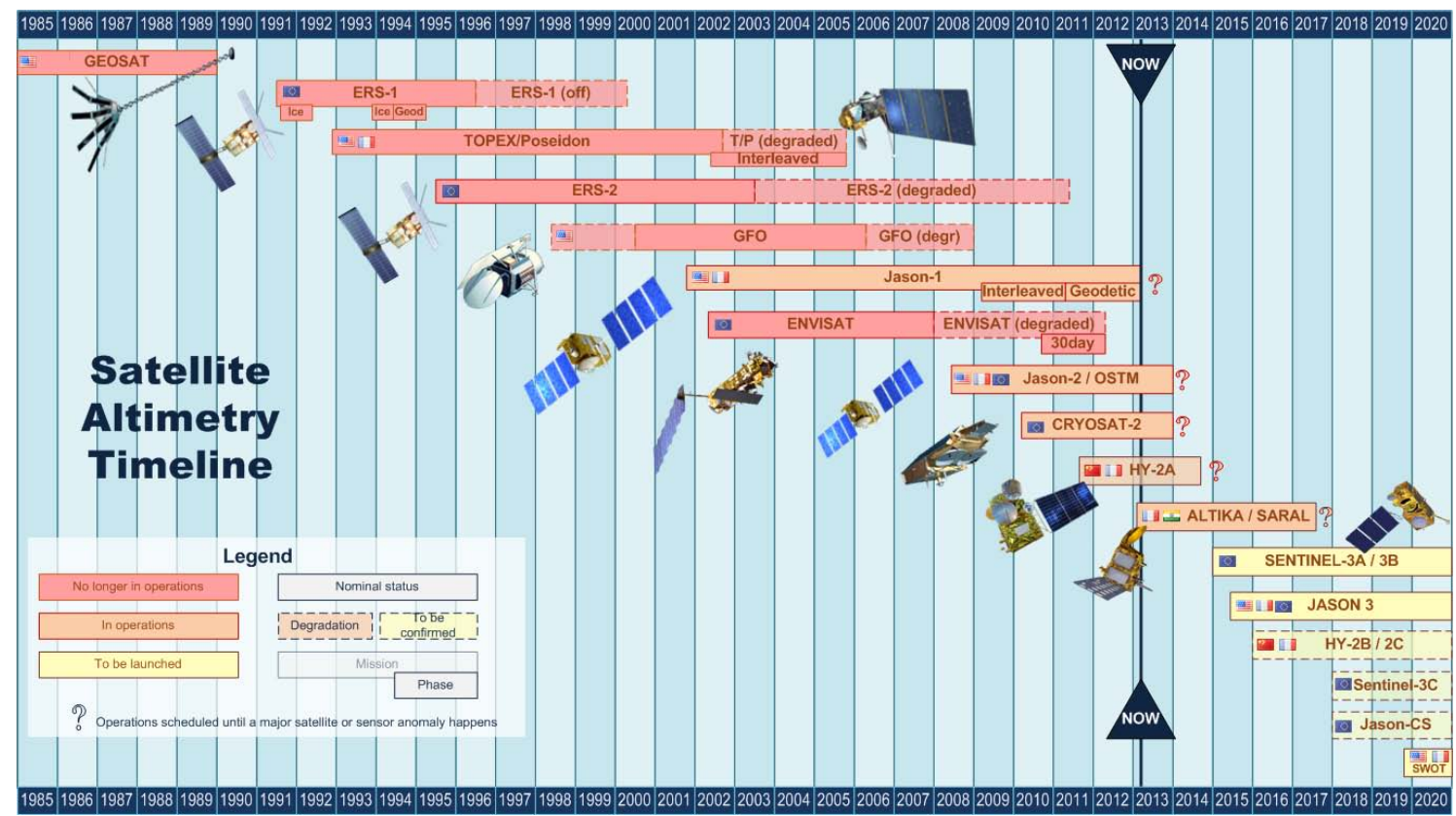

Fig. 1. Past, present and future altimeter missions (Courtesy G. Dibarboure).

Figure 1 provides a summary of existing and future altimeter missions.

\subsection{The challenge of high accuracy altimetry: the T/P breakthrough}

Satellite altimetry is also one of the most complex and challenging techniques in terms of accuracy. It requires measuring the distance between the satellite and the sea surface with an accuracy of a few $\mathrm{cm}$; assuming a typical satellite height of $1000 \mathrm{~km}$, this means a relative accuracy of $10^{-8}$. There have been major advances in sensor and processing algorithm performances over the last $20 \mathrm{yr}$. It is important to realize that these advances were only possible through a continuous dialogue between engineers and scientists. As a result, accuracy has evolved from several meters to a few cm only (Fig. 2). The essential role of the T/P Science Working Team (SWT) and later on of the Ocean Surface Topography Science Team (OST-ST) must be emphasized here. These strong and committed international scientific teams were dedicated to the improvement of altimeter performance for science investigations.

T/P provided a major advance in accuracy. Its payload (dual frequency altimeter for ionospheric corrections, three frequency radiometer and DORIS, GPS and laser tracking for satellite orbit determination) and orbit were optimized for sea level measurements. T/P orbit was at high altitude to reduce atmospheric drag effects, thus allowing a better orbit determination; it was chosen as a non-sun synchronous orbit with a repeat time period to reduce tidal aliasing problems and a $66^{\circ}$ inclination to allow a good observation of the two velocity components at crossovers. T/P orbit was known to have an accuracy of about $2 \mathrm{~cm}$ rms and the satellite-ocean surface distance could thus be determined to within a few $\mathrm{cm}$.

\subsection{2: a major milestone in the development of satellite altimetry}

The following events that occurred $20 \mathrm{yr}$ ago have had a major impact on the development of satellite altimetry:

- The publication of the so-called " purple book" The future of spaceborne altimetry: Oceans and Climate Change - A Long Term Strategy (Koblinsky et al., 1992). This visionary paper paved the way for the development of satellite altimetry over the next $20 \mathrm{yr}$. Its main recommendation was for "a succession of highaccuracy satellite altimeter systems designed for ocean and ice observations to establish an uninterrupted time series over the global ocean and major ice sheets for at least the subsequent $20 \mathrm{yr}$ ".

- The launch of TOPEX/Poseidon (T/P). T/P was optimized for large-scale sea level observations. T/P revolutionized our vision and understanding of the ocean.

- The start of the ERS-1 35-day repeat period mission, initializing together with TOPEX/Poseidon, a longterm $(20 \mathrm{yr})$ two-satellite altimeter constellation. The ERS-1 orbit was very well suited for mesoscale circulation and the sampling was quite complementary to $\mathrm{T} / \mathrm{P}$. 


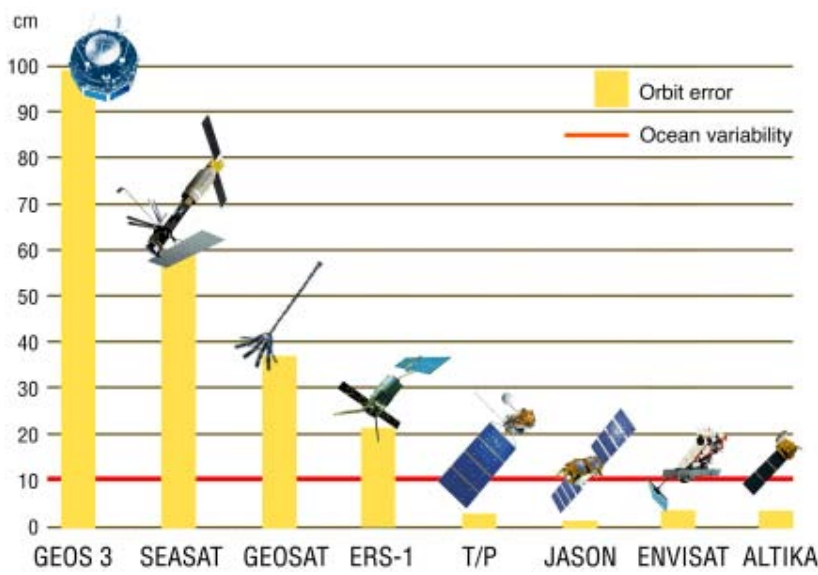

Fig. 2. Evolution of accuracy of altimeter missions.

\section{Science investigations from satellite altimetry}

Over the past $20 \mathrm{yr}$, sea level and ocean circulation science investigations from satellite altimetry have been swinging from mesoscale to large-scale focuses. A brief review is given here.

\subsection{GEOSAT: a mission well suited for mesoscale variability studies}

The 70s were often quoted as the mesoscale decade. Several major experiments were carried out in the USA (Mode and Polymode), in Russia (Polygon) and to a lesser extent in France (Tourbillon) to investigate mesoscale dynamics. In the pre-TOPEX/Poseidon era, mesoscale variability was thus a clear research focus. The GEOSAT ERM (19861990) was particularly suitable for mesoscale investigations. These resulted in major new findings. Many topics were covered from the almost three years of GEOSAT ERM observations: tracking of eddies (e.g. Gordon and Haxby, 1990; Jacobs and Leben, 1990), frequency/wave number spectra and space/time scales of variability (e.g. Le Traon et al., 1990; Stammer and Boening, 1992; Le Traon, 1991), eddy momentum fluxes (e.g. Tai and White, 1990; Morrow et al., 1992), model validation (e.g Wilkin and Morrow, 1994), eddy energy variations (e.g. Fu et al., 1988; Zlotnicki et al., 1989), western boundary currents (e.g. Kelly and Gille, 1990; Qiu et al., 1991). These topics have been revisited over the following $20 \mathrm{yr}$ and are still subject of intense research activities.

\subsection{TOPEX/Poseidon: large-scale variability is observed for the first time}

After the launch of TOPEX/Poseidon, the altimeter community mostly switched to large-scale variability analysis. TOPEX/Poseidon was also a centerpiece of WOCE (Wunsch, 2001), the World Ocean Circulation Experiment, which had a clear focus on the large-scale ocean circulation. T/P

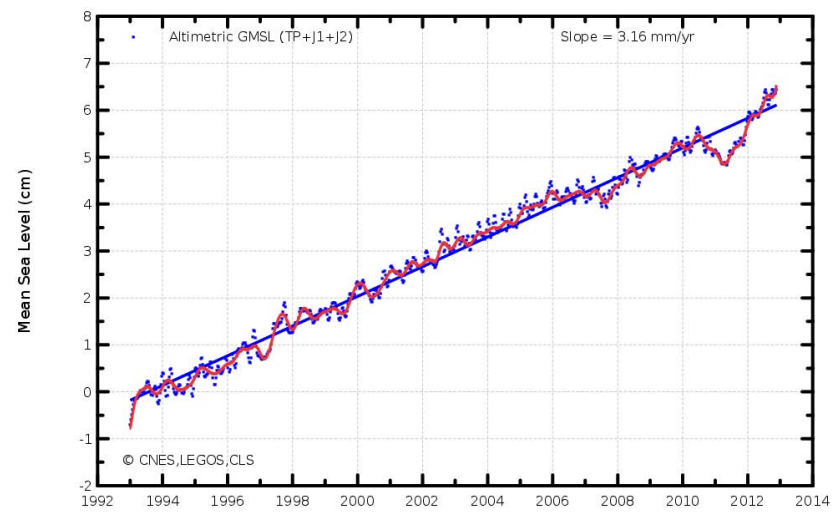

Fig. 3. Mean sea level variations over the 1992-2012 time period. The rise in mean sea level has been estimated as $3.17 \mathrm{~mm} \mathrm{yr}^{-1}$. Analysing the uncertainty of each altimetry correction made for calculating the GMSL, as well as a comparison with tide gauges gives an error in the GMSL slope of approximately $0.6 \mathrm{~mm} \mathrm{yr}^{-1}$ with a $90 \%$ confidence interval. (Credits CLS/CNES/LEGOS).

was the first altimeter mission optimized for large-scale sea level observations (e.g. Koblinsky et al., 1992). It provided for the first time a global description of the large-scale sea level and ocean circulation variations, mean sea level variations and El Niño/La Niña events (see Fu and Chelton, 2001; Picaut and Busalacchi, 2001; Cazenave and Nerem, 2004 for a review). These signals could not be or could be barely observed with previous altimeter missions. Large-scale seasonal steric sea level variations related to the heating/cooling of surface waters were the first signals discovered by $T / P$. Monitoring of tropical variability and Rossby and Kelvin wave propagation signals related to El Niño/La Niña events has been a major contribution. Characterization of the intraseasonal large-scale high-frequency variability was also another major finding of T/P. T/P also provided an invaluable contribution to the observation and modelling of tidal signals. The capability of estimating global mean sea level variations (e.g. Cazenave and Nerem, 2004) was somewhat unexpected. Due to a careful monitoring of error sources (see Ablain et al., 2009 for a recent review) and a continuous validation with tide gauge observations (e.g. Mitchum, 1998), the global mean sea level variations can now be monitored from space with T/P and its successors Jason- 1 and Jason2. Shown in Fig. 3 is a time series of the global mean sea level measured by T/P and Jason-1 and Jason-2 from 1992 to 2012. The rate of global mean sea level rise over this time period is about $3 \mathrm{~mm} \mathrm{yr}^{-1}$. Altimetry data also provide the first observation of the spatial variability of the mean sea level variations (Fig. 4). 


\subsection{End of the 90s: a renewed interest in mesoscale variability}

In the end of the 90s, the community interest switched back to mesoscale investigations. This renewed interest was partly related to the availability of multiple altimeter missions. Over the past $10 \mathrm{yr}$, most mesoscale studies have relied on the improved resolution derived from the SSALTO/DUACS merged T/P (resp. Jason-1) and ERS (resp. ENVISAT) data sets. These recent studies have provided new insights on eddy dynamics and their roles on ocean circulation, transport of heat and salt and coupling with atmosphere and biology. This has allowed a much better recognition and understanding of the role and importance of eddies. A few illustrative examples are given below. A comprehensive review is given in Le Traon and Morrow (2001), Fu et al. (2010) and Morrow and Le Traon (2012). The development of the SSALTO/DUACS merged products for mesoscale variability studies is described in the next section.

The improved resolution from T/P and ERS-1/2 (and later on Jason-1 and ENVISAT) has provided a characterization of the eddy kinetic energy (EKE) with a level of detail never before achieved at global scale (e.g. Ducet et al., 2000). It has also allowed a better characterization of space and time scales of mesoscale variability (e.g. Ducet et al., 2000; Jacobs et al., 2001), eddy propagation velocity (e.g. Brachet et al., 2004; Morrow et al., 2004; Fu, 2009; Chelton et al., 2007, 2011b), anisotropy (e.g. Ducet et al., 2000; Huang et al., 2007), skewness (e.g. Thompson and Demirov, 2006), a better description of eddy/mean flow interaction (e.g. Ducet and Le Traon, 2001; Qiu and Chen, 2010) and coupling with biology (e.g. Chelton et al., 2011b). This improved description of mesoscale variability has been extensively used to validate eddy permitting or eddy resolving models (e.g. Stammer et al., 1996; Brachet et al., 2004; Penduff et al., 2010). Brachet et al. (2004) showed the high level of agreement between POP $1 / 10^{\circ}$ North Atlantic model and altimeter observations. The spatial scales and eddy propagation velocities were also shown to match accurately.

Ducet et al. (2000) found a good comparison between velocities derived from altimeter and drifter data. Differences in EKE between altimetry and drifters were further analyzed by Fratantoni (2001) who explained differences mainly by sampling issues both for drifters and altimetry. Sampling effects for altimetry were quantified by Le Traon and Dibarboure (2002) (see Sect. 4.6). A few years later, Maximenko and Niiler (2006) pointed out that part of the differences was physical due to cyclostrophic effects. Geostrophic velocity (slightly) underestimates (overestimates) velocity in anticyclonic (cyclonic) eddies. Differences in EKE are thus highly correlated with sea level variability skewness (Thompson and Demirov, 2006). This is an interesting result that highlights the importance of a better understanding of observed signals. Note that altimeter data have recently been used to diagnose

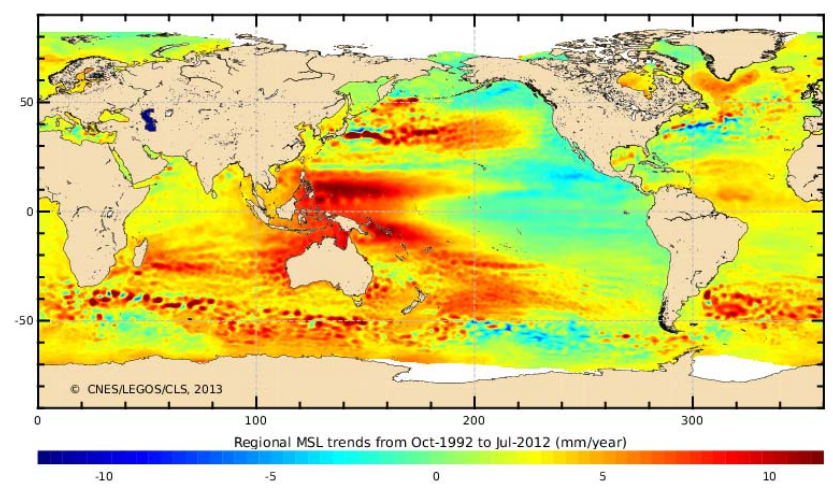

Fig. 4. Regional variations of mean sea level variations over the 1992-2012 time period (in $\mathrm{mm} \mathrm{yr}^{-1}$ ). This map is obtained using multi-mission SSALTO/DUACS gridded fields, which enable the local slopes to be estimated with a high resolution. (Credits CLS/CNES/LEGOS).

errors in global drifter array velocities due to drogue loss (Rio et al., 2011; Grodsky et al., 2011).

Merged T/P and ERS data sets have also allowed a better investigation of EKE seasonal variations. A very nice illustration is given in the Qiu and Chen (2004) study. They detected high EKE bands in the South Pacific with well-defined annual cycles along the eastward-flowing surface currents of the South Tropical Countercurrent (STCC) and the South Equatorial Countercurrent (SECC). They were able to relate these variations to the seasonal variation in the intensity of baroclinic and barotropic instabilities of the general circulation.

The availability of global merged altimeter products over a long time period and the development of eddy detection techniques have allowed a systematic tracking of individual eddies. Morrow et al. (2004) found divergent pathways of cyclonic and anti-cyclonic ocean eddies in the three oceans of the Southern ocean. Chelton et al. (2007, 2011b) carried out a global tracking and characterization of individual eddies. This outstanding analysis has contributed to a much better recognition of the importance of eddies. Thousands of eddies are observed in all regions of the world ocean and they can be monitored over long time periods and long distances. The non-linear characteristics of eddies make it clear that the dynamics of mid-latitude variability is not dominated by Rossby wave propagation.

Understanding the shape of wave number spectra has been revisited based on improved data sets, very high resolution models and new theoretical developments. Le Traon et al. (2008) showed that wave number sea level spectral shapes in high eddy energy regions are close to $k^{-11 / 3}$ and thus favour an interpretation in terms of surface quasi geostrophic (SQG) dynamics (Lapeyre and Klein, 2006). Xu and Fu (2012) carried out a global estimation of altimeter wave number spectral slopes taking into account white altimeter noise. They found similar wave number slopes in high eddy energy 
regions. In low eddy energy regions, slopes are much weaker and close to $k^{-2}$. This is consistent with previous estimations based on Geosat data (e.g. Le Traon et al., 1990). Arbic et al. (2012) and Richman et al. (2012) recently pointed out the role of internal tides that could explain the flatter slopes.

Finally, a new interesting finding from merged altimeter data sets is the ubiquitous presence of jet-like structures in the anomalies of geostrophic velocity (Maximenko et al., 2005,2008 ). The underlying physical mechanisms are not yet fully understood yet but are likely to be related to the development of $\beta$ plumes.

\section{History of the development of the SSALTO/DUACS merged products}

Over the past $20 \mathrm{yr}$, the simultaneous availability of several altimeter missions and the development of merging techniques have offered unique capabilities to observe the ocean at high resolution. Near-real-time high-resolution global sea level anomaly maps have been operationally produced as part of the SSALTO/DUACS system. They are now widely used by the oceanographic community and have contributed to a much better understanding and recognition of the role and importance of mesoscale dynamics. Merging multiple altimeter data sets is not, however, an easy task and the development of merged products has been a long-term and time consuming effort. An historical background is given in the following sections.

\subsection{First step: demonstrating that $T / P$ data could be used to improve ERS}

In 1992, ERS-1 was flying simultaneously with T/P. The space/time sampling by these two missions was quite complementary. The ERS- 1 orbit with a 35 day repeat cycle was well suited for mesoscale studies while the T/P orbit was optimized for large-scale signal observations. Compared to T/P, ERS-1 was a less precise altimeter mission. The accuracy of ERS-1 near-real-time orbits was, in particular, only about $30 \mathrm{~cm}$ rms mainly because of the failure of the PRARE orbit tracking system. Merging of ERS- 1 and T/P thus first required reducing the large-ERS-1 orbit error. Using the more precise T/P data as a reference, one could improve the accuracy. Together with CLS colleagues, I started working on the problem in early 1994 and made a first successful demonstration in 1995 (Le Traon et al., 1995a, b). Through a global minimization of T/P-ERS and ERS-ERS crossover differences, we showed that ERS orbit error could be reduced to a level comparable to the T/P orbit error. In addition, the method allowed removal of any biases between the two missions. Several ERS-1 cycles were reprocessed and corrected for using $\mathrm{T} / \mathrm{P}$ as a reference.
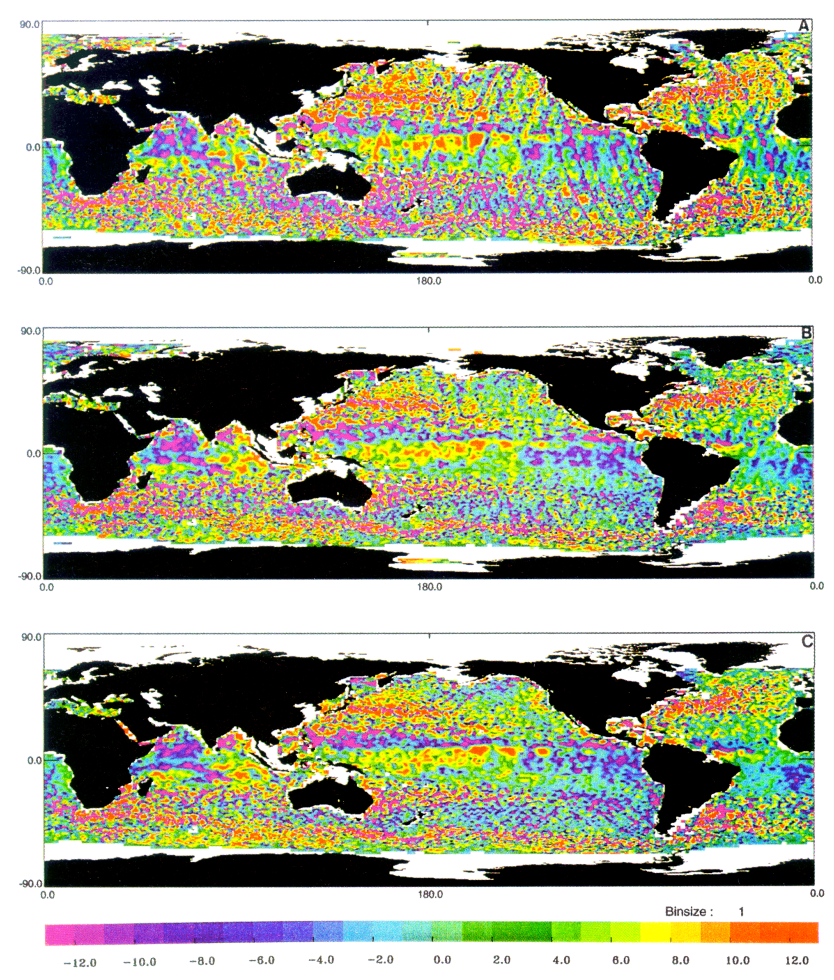

Fig. 5. ERS orbit error reduction using TOPEX/Poseidon as a reference. The impact of the correction is shown on a map of sea level anomaly derived from ERS observations at a given day without (upper figure) and with (middle figure) the correction. This can be compared to the map derived from TOPEX/Poseidon observations (bottom figure). (from Le Traon and Ogor, 1998). Units are $\mathrm{cm}$.

\subsection{Second step: reprocessing of whole ERS time series}

The next step was to convince funding agencies to reprocess the entire ERS time series and set up an operational multiple altimeter processing system. This was not an easy task. It was not clear who should fund such an activity. Space agencies did not consider the development of high-level multimission products as their responsibility. Several user surveys were carried out as part of the CEO (Center for Earth Observation) programme of the European Commission (the socalled pathfinder and proof of concept studies coordinated by CLS and carried out in 1995/1996). Thanks to the French Space Agency (CNES) and several European projects (e.g. AGORA, MATER, CANIGO), the merging methods were developed further (e.g. Hernandez et al., 1995; Ayoub et al., 1998). The whole ERS time series was reprocessed and adjusted onto T/P data (Le Traon and Ogor, 1998). The adjustment method was refined and its formal error was derived. We demonstrated that the ERS orbit could be derived with an accuracy similar to that of T/P ("the $2 \mathrm{~cm}$ challenge") (Fig. 5). 

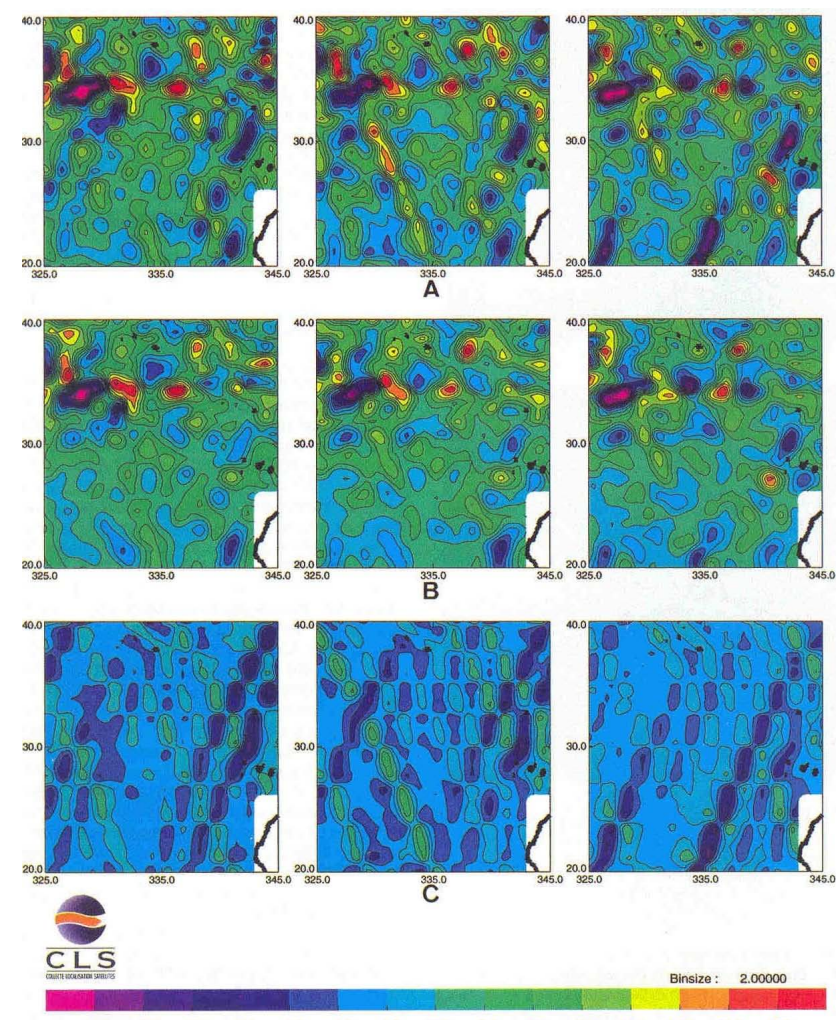

$\begin{array}{lllllllllllllll}-11.0 & -9.0 & -7.0 & -5.0 & -3.0 & -1.0 & 1.0 & 3.0 & 5.0 & 7.0 & 9.0 & 11.0 & 13.0 & 15.0 & 17.0\end{array}$

Fig. 6. Map of sea level anomaly derived from ERS-1 (right), T/P (middle) and T/P+ERS-1 (left) with a conventional mapping technique (upper panel) and a mapping technique that takes into account long wavelength (correlated) errors (middle panel). Differences between maps are shown in the lower panel. (from Le Traon et al., 1998). Units are cm.

\subsection{Third step: development of the global mapping technique}

The global mapping technique was developed in parallel (Le Traon et al., 1998). The method is a global space/time suboptimal interpolation method (e.g. Bretherton et al., 1976) that uses an a priori knowledge of space and time scales of sea level variations (covariance). These were derived from the analysis of altimeter observations. Noise characterization was essential and included measurement white noise, unresolved (small scale) signals and correlated noise due to errors in models used to correct altimeter observations mainly from tidal and high-frequency effects due to atmospheric pressure and wind forcing. The main originality of the method was to take explicitly into account these correlated errors in the mapping procedure. This resulted in a major improvement in the mapping of eddy sea level and velocity signals (Fig. 6). The first global maps of T/P and ERS-1/2 data were then produced by Ducet et al. (2000).

\subsection{Fourth step: real-time processing and DUACS project}

The near-real-time processing of altimeter data was developed as part of DUACS (Developing Use of Altimetry for Climate Studies), a European Commission Project 3-yr project which started in February 1997. DUACS was part-funded under the CEO Programme of the Environment and Climate programme of the European Commission and the Midi-Pyrénées regional council. It was coordinated by Philippe Gaspar at CLS, and gathered four of the major climate research teams in Europe: the European Centre for Medium-Range Weather Forecasts (ECMWF), the European Centre for Research and Advanced Training in Scientific Computation (CERFACS), the UK Met. Office (UKMO) and the Max-Planck Institute für Meteorologie (MPIFM). This was a major step forward. DUACS project demonstrated that altimeter data can be processed in near-real-time with sufficient accuracy for operational oceanography and to help improve the skill of climate simulations and, more specially, seasonal climate forecasts.

\subsection{Final step: the operational SSALTO/DUACS products}

In 2002, DUACS was integrated in the CNES multi-satellite ground segment (SSALTO) processing facility. This final step allowed DUACS to move from a project to a sustained operational system SSALTO/DUACS. The system was then regularly improved through different R\&D or operational projects (e.g. ENACT, MERSEA, MyOcean).

Thanks to SSALTO/DUACS, we now have a long time series $(20 \mathrm{yr})$ of high-resolution mesoscale altimeter products based on a homogenous two satellite configuration (T/P and ERS-1/2 and Jason-1/2 and ENVISAT). These products have been used for a wide range of science and operational applications (see previous section): mesoscale variability and global characterization of eddies, monitoring fronts in the Antarctic Circumpolar Current, multiple migrating quasi zonal jets, eddies and Rossby waves, ocean-atmosphere coupling at the mesoscale, model validation, testing turbulence theories, coupling physics and biology, coastal dynamics, Argo and altimetry, data assimilation, operational oceanography and applications.

SSALTO/DUACS is now the main multi-mission altimeter data center used by the scientific community and by operational oceanography and climate centers. It provides directly usable, high quality near-real-time and delayed-mode global and regional altimeter products. Main processing steps include product homogenization, data editing, orbit error correction, reduction of long wavelength errors, and production of along-track and mapped sea level anomalies. A mean dynamic topography (MDT) is also used to obtain absolute dynamic topographies. Several versions of MDTs were derived and the most recent ones benefit from GRACE and GOCE 
observations (e.g. Rio et al., 2011). The SSALTO/DUACS weekly production moved to a daily production in 2007 to improve timeliness of data sets and products. A new real-time product was also developed for specific real-time mesoscale applications. A comprehensive recent description of SSALTO/DUACS is given in Dibarboure et al. (2011).

In 2011, more than 2000 users were registered with access to the SSALTO/DUACS products and more than 80 publications in the international literature have used these products. The use of merged altimeter products is now commonplace. This was not at all the case $20 \mathrm{yr}$ ago and the user requirements have strongly evolved based on the availability of products. This is one of the lessons of the SSALTO/DUACS history.

Many colleagues at CLS (engineers and scientists), Phd students and postdocs with different and complementary skills contributed to the development and scientific use of SSALTO/DUACS products. This was essential for transforming a scientific demonstration product into a widely used and operational product. Long-term support from CNES was essential.

\subsection{What do multiple altimeters resolve? How many altimeters are needed?}

The minimum requirement for ocean variability sampling by altimetry is that at least two altimeter missions with one very precise long-term altimeter system are needed (e.g. Koblinsky et al., 1992). With the T/P and Jason-1 and ERS and ENVISAT missions, this minimum requirement has been met since 1992. Le Traon and Dibarboure (2002) provide a summary of the mapping capabilities of the T/P+ERS (Jason$1+$ ENVISAT) configuration. Sea level can be mapped with an error of less than $10 \%$ of the signal variance while the velocity can be mapped with an error of 20 to $40 \%$ of the signal variance (depending on latitude). A large part of mapping errors is due to high-frequency (periods $<20$ days) and highwave numbers signals (wavelengths $<100-200 \mathrm{~km}$ ). There was a stimulating debate in the early 2000s on the resolution capability of multiple altimeter data. This is a complex issue because the sampling is irregular in space and time and the measurement errors add a significant burden. Several theoretical studies were carried out (e.g. Wunsch, 1989; Chelton and Schlax, 1994; Greenslade et al. 1997; Le Traon and Dibarboure, 1999, 2002; Le Traon et al., 2001a; Tai, 2004, 2006). Different views were expressed. They often were related to different interpretations of what is meant by resolution. There is now a common agreement that the merging of multiple altimeter data sets (two satellites in delayed mode) resolve sea level wavelengths longer than $200 \mathrm{~km}$.

Although the $\mathrm{T} / \mathrm{P}+\mathrm{ERS}$ merged data have provided a much better representation of the mesoscale variability, it is far from fully resolving the mesoscale variability. To improve further our understanding of mesoscale variability, one must observe it at higher space and time resolution. From
October 2002 to September 2005, sampling of the ocean has been exceptional with four altimeter missions flying simultaneously (Jason-1, ENVISAT, T/P interleaved with Jason1 and Geosat Follow-On). These data sets were merged to improve the estimation of mesoscale surface circulation in the Mediterranean Sea and in the global ocean by Pascual et al. (2006, 2007). These studies demonstrated that, at least three, but preferably four, altimeter missions are needed for monitoring the mesoscale circulation. The effect is much larger for real-time applications. Pascual et al. (2009) showed that four altimeters are needed in real time to get a similar quality performance as two altimeters in delayed mode.

\section{Argo}

\subsection{Development of Argo}

Satellite altimetry is only one, albeit major, element of the global ocean observing system. A major challenge in the end of the 90s was to set up a real-time global in situ observing system to complement satellite observations. This led to the development of Argo, a global array of profiling floats measuring every 10 days temperature and salinity throughout the deep global oceans, down to $2000 \mathrm{~m}$. Argo was initially developed as a joint venture between GODAE and CLIVAR (Argo Science Team, 1998; Roemmich et al., 1999). It has been an outstanding achievement and a second revolution in oceanography. In November 2007, Argo reached its initial target of 3000 profiling floats. More than 30 countries are involved in the development and maintenance of the array. Argo delivers data both in real time for operational users and after careful scientific quality control for climate change research and monitoring. The outstanding scientific leadership of Dean Roemmich, a strong international cooperation and a highly committed international Argo steering-science team are key elements of such a major success.

There were stimulating discussions on the development and organisation of Argo in its initial phase. I contributed with French colleagues on design and sampling issues at an international level (Argo Science Team and GODAE) and at national level (Coriolis and Mercator Ocean) (e.g. Guinehut et al., 2002, 2004). An important debate took place on the initial scope of Argo: should Argo start with a North Atlantic array or should Argo go directly to a global array? Argo was finally developed as a global array. The value of being global has been widely demonstrated through Argo results and achievements. This was also a strong requirement given by the GODAE community (e.g. Le Traon et al., 2001b).

\subsection{Argo achievements}

Freeland (2010) provides an overview of early Argo achievements. Argo data have been used to better understand global sea level rise (e.g. Cazenave et al., 2009), to analyze largescale ocean circulation variations (e.g. Roemmich et al., 


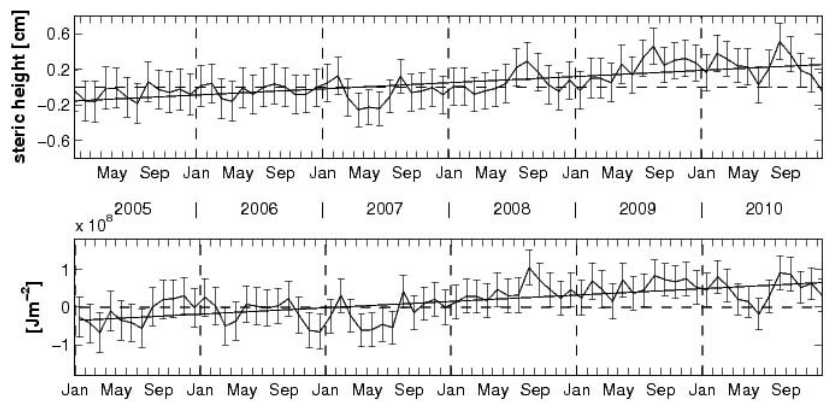

Fig. 7. Global ocean heat content and mean steric sea level variations derived from Argo data (2005-2010) (from von Schuckmann and Le Traon, 2011).

2007) and deep convection areas (e.g. Väge et al., 2009). Argo provides a major improvement in the estimation of heat stored by the oceans (e.g. von Schuckmann et al., 2009; Trenberth, 2010; von Schuckmann and Le Traon, 2011). This is crucial for a better understanding of the earth energy balance (e.g. Hansen et al., 2011). Argo data in relation to the historical record have also shown salinity changes that suggest an amplification of the global hydrological cycle (Durack and Wijffels, 2010). Argo has brought remarkable advances in ocean forecasting capability (e.g. Oke et al., 2009; Dombrowsky et al., 2009) (see next section) and will be critical for developing reliable seasonal to decadal climate predictions (e.g. Balmaseda et al., 2007; Balmaseda and Anderson, 2009). About 200 papers using Argo data are published per year. Research papers often jointly use Argo and altimetry. Argo data are also now systematically used together with altimeter data for ocean analysis and forecasting. This demonstrates the very strong and unique complementarity of the two observing systems.

\subsection{Synergies with altimetry}

Argo has strong complementarities with satellite altimetry. Improved ocean heat storage derived from Argo (e.g. von Schuckmann et al., 2009; von Schuckmann and Le Traon, 2011) (Fig. 7) is needed for a better understanding of the mechanisms behind mean sea level rise. This is an example of the strong complementarity with altimetry (and GRACE). Guinehut et al. (2006) and Dhomps et al. (2011) have shown how barotropic and deep steric signals at different timescales can be inferred from the comparison of Argo and altimetry. Another interesting example of the synergetic use of altimeter and Argo is the use of altimeter data in Argo quality control (Guinehut et al., 2009). This quality control is now part of the operational Coriolis processing system.

I have also been working with Stéphanie Guinehut and Gilles Larnicol for the last $10 \mathrm{yr}$ on the development of products merging Argo and altimeter observations (Guinehut et al., 2004, 2012). The objective was to use altimetry, satellite sea surface temperature (SST) and Argo observations to reconstruct 3-D mesoscale temperature and salinity fields. Argo observations allow a global description of the statistical relationships that exist between surface and subsurface fields needed to infer the 3-D T\&S fields from altimetry and SST. Compared to the use of climatological estimates, up to $50 \%$ of the variance of the temperature fields in the upper layers can thus be reconstructed from altimeter and sea surface temperature observations and a statistical method (Guinehut et al., 2012). For salinity, only about 20 to $30 \%$ of the upper layers signal can be reconstructed from satellite observations. We showed then that the joint use of Argo, altimeter and SST observations improves further the 3-D mesoscale temperature and salinity fields by 20 to $30 \%$ of the signal variance (Fig. 8). We also showed that the joint use of Argo and altimetry provides a better reconstruction of large-scale and low-frequency fields due to a better reduction of the aliasing of the mesoscale variability. This was shown in a simulation study by Guinehut et al. (2004) and verified with actual data by Guinehut et al. (2012).

\subsection{European contributions}

Over the past couple of years, I have been involved with Ifremer and European colleagues in the development of the Euro-Argo research infrastructure that organizes and federates the European contribution to Argo (http://www. euro-argo.eu). Euro-Argo is part of the European Strategy Forum on Research Infrastructures (ESFRI) roadmap. It will develop and progressively consolidate the European component of the global network. We set up an initial target: the European contribution should be of the order of a quarter of the global array. Specific European interest also requires an increased sampling in the Nordic, Mediterranean and Black Seas. Overall, this will require Europe to deploy about 250 floats per year. The objective is also to prepare the next phase of Argo in Europe with the extension to biogeochemical variables, the deep ocean, marginal seas and the polar seas. Euro-Argo has been designed to answer needs from ocean and climate research and operational oceanography (GMES/Copernicus) communities. In 2013, Euro-Argo will evolve into a long-term European organization and legal structure (Euro-Argo ERIC) that will be initially hosted by France. This new European legal structure will allow European countries to improve their contribution to Argo. Agreements are at ministerial level and this will help to ensure long-term sustainability. This is the first time a European legal entity is set up to develop the global ocean observing system in Europe. This is a unique opportunity to consolidate the European contribution to Argo. Argo France is the French component of Euro-Argo. It is organized through the multiagency Coriolis partnership and is now part of the Ministry of Research national roadmap on large research infrastructures (TGIR). 

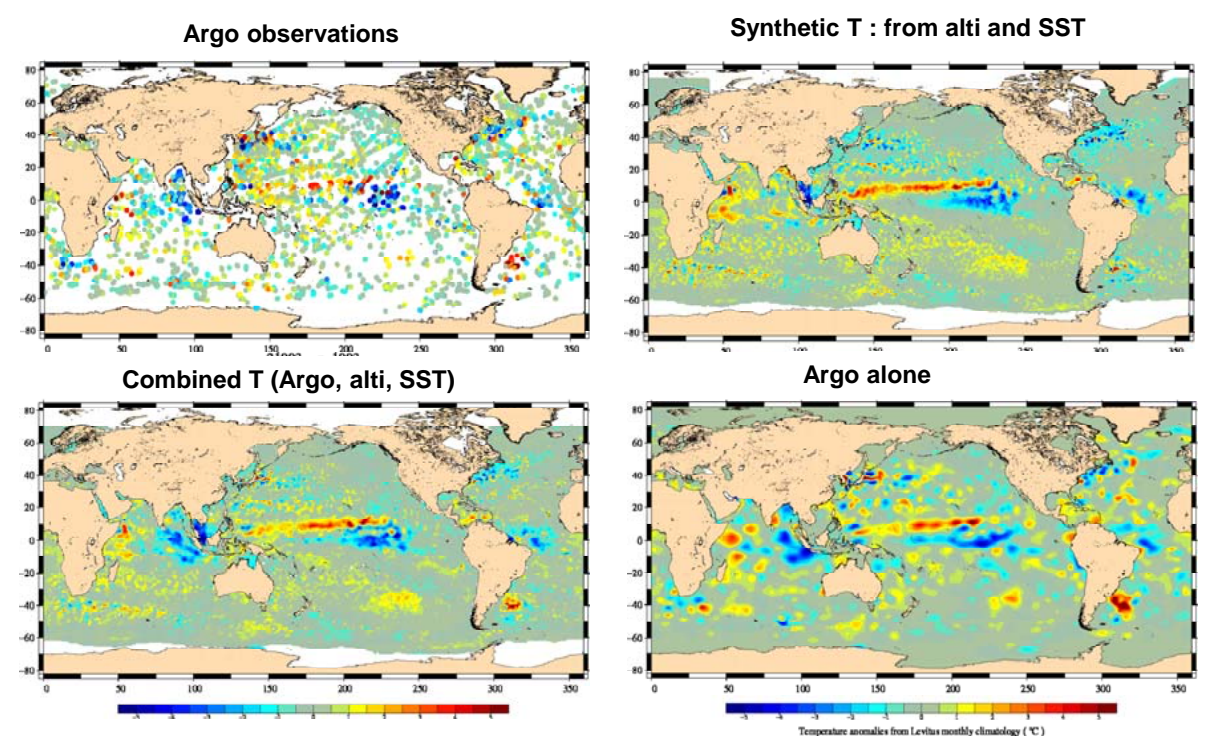

Fig. 8. Use of Altimetry, SST and Argo observations to reconstruct 3-D mesoscale temperature fields. Temperature field at $200 \mathrm{~m}$ (in ${ }^{\circ} \mathrm{C}$ ) at a given day derived from SST and altimeter observations (upper right), Argo observations alone (lower right) and combined Argo, altimeter and SST observations (lower left). Argo observations are shown on the upper left panel (from Guinehut et al., 2012).

\section{Operational oceanography and GODAE}

There are very strong links between satellite altimetry and operational oceanography. The ability to observe the global ocean in near-real-time at high space and time resolution is a prerequisite to the development of global operational oceanography and its applications. In addition to providing all weather observations, sea level from satellite altimetry is an integral of the ocean interior and provides a strong constraint on the 4-D ocean state estimation. At the end of the 90 s, the satellite altimetry community was keen to develop further the use of altimetry and this required an integrated approach merging satellite and in situ observations with models. The Global Ocean Data Assimilation Experiment (GODAE) was thus set up in 1997 (Smith and Lefebvre, 1997). The vision was "A global system of observations, communications, modelling and assimilation, that will deliver regular, comprehensive information on the state of the oceans, in a way that will promote and engender wide utility and availability of this resource for maximum benefit to the community" (International GODAE Steering Team, 2000). The aim was to demonstrate the feasibility and utility of global ocean monitoring and forecasting and to assist in building the infrastructure for global operational oceanography.

\subsection{GODAE development and achievements}

GODAE has been a major breakthrough in oceanography. The GODAE demonstration (2002-2008) was phased with the Jason-1 and ENVISAT altimeter missions. GODAE has had a major impact on the development of global operational oceanography capabilities (Bell et al., 2009). It was instrumental in the development of Argo and GHRSST (GODAE High Resolution Sea Surface Temperature) (GODAE pilot projects), altimetry and in situ data processing systems (e.g. SSALTO/DUACS and Coriolis). Global modelling and data assimilation systems were progressively developed, implemented and inter-compared. In situ and remote sensing data have been routinely assimilated in global and regional ocean models to provide an integrated description of the ocean state. Products and services were developed for a wide range of applications: marine environment monitoring, weather forecasting, seasonal and climate prediction, ocean research, maritime safety and pollution forecasting, national security, the oil and gas industry, fisheries management and coastal and shelf-sea forecasting (see GODAE Oceanography Magazine Special Issue - Bell et al., 2009).

\subsection{The role of observations}

Ocean analysis and forecasting models are strongly dependent on the availability of multiple altimeter data and Argo observations. High-resolution altimetry is mandatory to constrain the mesoscale circulation. Three to four altimeters at least are required (see also discussion above). Model resolutions are typically $1 / 12^{\circ}$ and $1 / 36^{\circ}$ at global and regional scales, respectively. This poses even stronger requirements for the altimeter constellation. Argo and the global in situ observing system are mandatory to constrain large-scale temperature and salinity fields that are poorly constrained by satellite observations. Although Argo does not resolve the mesoscale, the joint use of Argo and altimetry through effective data assimilation techniques can provide a good representation of mesoscale temperature and salinity fields (see 
also Sect. 5.3). This was initially anticipated (e.g. Le Traon et al., 2001b) and was demonstrated as part of GODAE. The capability of Argo to complement altimeter observations to constrain both large-scale and mesoscale ocean fields through data assimilation is a major asset and explains why these two observing systems now provide the backbone of the global observations for operational oceanography. A review of the role of altimeter and Argo observation data to constrain global ocean models is given by Oke et al. (2009). A continuous assessment of the impact of Argo and altimeter observations is now organized at international level through GODAE OceanView.

\subsection{French and European contributions}

The French contribution to GODAE was developed in early 1996 with the development of the Mercator modelling and data assimilation center, the in situ component with the multi-agency Coriolis structure and with the satellite component with CNES leadership in the development of the Jason series. Strong links with the research community were organized from the start. This was an essential ingredient for developing state of the art modelling and data assimilation systems and to ensure that operational oceanography systems are also designed to answer present and future research needs. The development of a coastal operational oceanography prototype system (Previmer) was started in a second phase in 2005.

In Europe, the MERSEA project allowed us to develop further the integration of European contributions to GODAE (Johannessen et al., 2006). This led to the development of the GMES/Copernicus Marine Service which is a major initiative to set up a sustained capability to observe and forecast the global ocean and European regional seas. Strong links were developed with EuroGOOS, in particular, to develop the upstream in situ observing system infrastructure and national downstream capabilities (e.g. coastal). The past $20 \mathrm{yr}$ have thus seen the development of a well-structured operational oceanography community at European level (science, observations, modelling and applications) from global, regional and coastal scales.

\subsection{The role of the International GODAE Steering Team}

GODAE started thanks to the leadership and initial vision of Neville Smith and Michel Lefebvre. The role of the International GODAE Steering Team has then been central. It was formed in 1997 and took the responsibility for the development of GODAE under the responsibility of Neville Smith. From 2005 to 2008, I co-chaired the IGST together with Mike Bell. Many scientists have served as members and contributed greatly to the success of GODAE. There was an excellent "spirit" and willingness to share data and products, expertise and experience (GODAE common). The team was supported by the GODAE Patrons (sponsors) and an active project office. Several symposia and summer schools were organized. At the end of GODAE in 2008 after the GODAE final symposium in Nice, it was decided to move towards a long-term program: GODAE OceanView which is now led by a new Science Team co-chaired by Andreas Schiller and Eric Dombrowsky. GODAE OceanView now ensures a longterm international coordination of operational oceanography and its evolution in relationship with JCOMM and GOOS.

\section{Conclusions and perspectives}

The 1992-2012 time period represents $20 \mathrm{yr}$ of outstanding achievements in oceanography: satellite altimetry, Argo, global operational oceanography and GODAE. This has had a major impact on oceanography. This was also the birth of a new community. These three major successes were closely linked and did not happen by chance. They resulted from an initial vision of the long-term evolution of oceanography building on previous achievements such as WOCE (World Ocean Circulation Experiment). This has been a well thought out and planned approach for the joint development of satellite, global in situ observations and modelling capabilities.

Several important lessons can be learnt from these successes. A long-term vision shared with the wider community and the ability to work together for a common cause with a shared sense of purpose and achievement are essential. The importance of international collaboration and, in particular, the specific role of strong and committed international science teams such as T/P SWT and OST-ST, Argo and GODAE must be emphasized. Synergies between fundamental and applied research, technology and applications are other important ingredients; this requires working with people with different and complementary skills. Continuity of infrastructure (observing systems, modelling and data assimilation) and, just as important, continuity of qualified teams is critical. This requires long-term (> $10 \mathrm{yr}$ ) support and high-level advocacy in national, European and international agencies.

Many challenges remain. Consolidating/sustaining the global ocean observing system is still a concern. There is still need to optimize and improve (better space/time sampling) the altimeter constellation. The altimetry community now has a much better understanding and recognition of the value of multiple altimeters. Operational oceanography now uses high to very high-resolution models with data assimilation. This poses much stronger requirements for an altimeter constellation. Today, we are almost facing similar challenges as $20 \mathrm{yr}$ ago and the altimeter constellation is not significantly improved. Observation capabilities lag behind. It is critical to ensure a long-term optimized high-resolution operational altimeter system for the next decade. Success of the development of GMES/Copernicus in Europe with the advent of Sentinel-3 missions and the development of the Jason-CS series (continuation of the Jason-1-2-3 series) is 
thus essential. We also need to maintain our collective expertise and efforts on instrument development, quality monitoring, intercalibration and the development of high-level products. Sustaining Argo and the global in situ ocean observing system is needed in parallel. The first priority is to consolidate the contribution to the Argo core mission (global temperature and salinity measurements down to $2000 \mathrm{~m}$ ) (Roemmich et al., 2009). This is critical to fully realize the unique and enormous potential of Argo. The European contribution should be significantly improved and this is the expectation from the Euro Argo research infrastructure. There is also a need to ensure the consolidation and evolution of operational oceanography services (e.g. GODAE OceanView, GMES/Copernicus Marine Service). This requires consolidating our modelling/assimilation capabilities and ensuring a continuous and state of the art $R \& D$ program.

There are also a series of new scientific challenges. The very high-resolution and submesoscale dynamics is a new scientific frontier. The future SWOT mission should allow us to address the observational component. Other components must be developed in parallel: the development of very high-resolution modelling (1 km at the global scale) and new theoretical frameworks for a better understanding of submesoscale dynamics, vertical motions and their role for the coupling between physics and biology. It is also critical to prepare the main evolutions of Argo for the next decade: biogeochemical observations, deeper measurements, under-ice operations in the polar seas and sampling of marginal seas. All of these evolutions are essential to improve our knowledge of the role of the ocean on climate. They are also required for operational oceanography. Operational oceanography finally needs to move its focus from physics to ecosystems (further integration) and from large scale to coastal scale both for observations, modelling, data assimilation and services. This calls for new international and European initiatives.

Acknowledgements. I feel very much honored to receive the prestigious Nansen medal. I consider it as recognition for a truly collective work, in particular, of the satellite altimetry community. Thanks to many outstanding colleagues and friends at CLS, CNES, Ifremer, Mercator Ocean and in the T/P and OST, Argo and GODAE international science teams. A particular thanks to the entire CLS Space Oceanography Division where I truly enjoyed $20 \mathrm{yr}$ of mutual adventure.

Edited by: N. Wells

\section{References}

Ablain, M., Cazenave, A., Valladeau, G., and Guinehut, S.: A new assessment of the error budget of global mean sea level rate estimated by satellite altimetry over 1993-2008, Ocean Sci., 5, 193 201, doi:10.5194/os-5-193-2009, 2009.

Arbic, B. K., Richman, J. G., Shriver, J. F., Timko, P. G., Metzger, E. J., and Wallcraft, A. J.: Global modeling of internal tides within an eddying ocean general circulation model, Oceanography, 25, 20-29, 2012.

Argo Science Team: On the Design and Implementation of Argo: An Initial plan for a Global Array of profiling Floats. International CLIVAR Project Office Report Number 2, GODAE Report No. 5, GODAE International Project Office, Melbourne, Australia, 1998.

Ayoub, N., Le Traon, P. Y., and De Mey, P.: Combining ERS-1 and TOPEX/Poseidon data to observe the variable oceanic circulation in the Mediterranean sea, J. Marine Syst., 18, 3-40, doi:10.1016/S0924-7963(98)80004-3, 1998.

Balmaseda, M. and Anderson, D.: Impact of initialization strategies and observations on seasonal forecast skill, Geophys. Res. Lett., 36, L01701, doi:10.1029/2008GL035561, 2009.

Balmaseda, M., Anderson, D., and Vidard, A.: Impact of Argo on analyses of the global ocean, Geophys. Res. Lett., 34, L16605, doi:10.1029/2007GL030452, 2007.

Bell, M. J, Lefebvre, M., Le Traon, P. Y., Smith, N., and WilmerBecker, K.: The Global Ocean Data Assimilation Experiment, Oceanography, 22, 14-21, 2009.

Brachet, S., Le Traon, P. Y., and Le Provost, C.: Mesoscale variability from a high-resolution model and from altimeter data in the North Atlantic Ocean. J. Geophys. Res., 109, C12025, doi:10.1029/2004JC002360, 2004.

Bretherton, F. P., Davis, R. E., and Fandry, C. B.: A technique for objective analysis and design of oceanographic experiment applied to MODE-73, Deep-Sea Res., 23, 559-582, 1976.

Cazenave, A. and Nerem, R. S.: Present-day sea level change: Observations and causes, Rev. Geophys., 42, RG3001, doi:10.1029/2003RG000139, 2004.

Cazenave, A., Dominh, K., Guinehut, S., Berthier, E., Llovel, W., Ramillien, G., Ablain, M., and Larnicol, G.: Sea level budget over 2003-2008: A reevaluation from GRACE space gravimetry, satellite altimetry and Argo, Global Planet. Change, 65, 83-88, 2009.

Chelton, D. B. and Schlax, M. G.: The resolution capability of an irregularly sampled dataset: with application to Geosat altimeter data, J. Atmos. Ocean. Tech., 11, 534-550, 1994.

Chelton, D. B., Ries, J. C., Haines, B. J., Fu, L. L., and Callahan, P. S.: Satellite Altimetry, Satellite altimetry and Earth sciences, in: Academic Press, edited by: Fu, L. L. and Cazenave, A., 2001.

Chelton, D. B., Schlax, M. G., Samelson, R. M., and de Szoeke, R. A.: Global observations of large oceanic eddies, Geophys. Res. Lett., 34, L15606, doi:10.1029/2007GL030812, 2007.

Chelton, D. B., Gaube, P., Schlax, M. G., Early, J. J., and Samelson, R. M.: The influence of nonlinear mesoscale eddies on nearsurface chlorophyll, Science, 334, 328-332, 2011a.

Chelton, D. B., Schlax, M. G., and Samelson, R. M.: Global observations of nonlinear mesoscale eddies, Prog. Oceanogr., 91, 167-216, 2011b.

Dhomps, A.-L., Guinehut, S., Le Traon, P.-Y., and Larnicol, G.: A global comparison of Argo and satellite altimetry observations, Ocean Sci., 7, 175-183, doi:10.5194/os-7-175-2011, 2011.

Dibarboure, G., Pujol, M.-I., Briol, F., Le Traon, P.-Y., Larnicol, G., Picot, N., Mertz, F., and Ablain, M.: Jason-2 in DUACS: Updated System Description, First Tandem Results and Impact on Processing and Products, Mar. Geod., 34, 214-241, doi:10.1080/01490419.2011.584826, 2011. 
Dombrowsky, E., Bertino, L., Brassington, G. B., Chassignet, E. P., Davidson, F., Hurlburt, H. E., Kamachi, M., Lee, T., Martin, M. J., Mei, S., and Tonani, M.: GODAE Systems in Operation, Oceanography, 22, 80-95, 2009.

Ducet, N. and Le Traon, P. Y.: A comparison of surface eddy kinetic energy and Reynolds stresses in the Gulf Stream and the Kuroshio Current systems from merged TOPEX/Poseidon and ERS-1/2 altimetric data, J. Geophys. Res., 106, 16603-16622, 2001.

Ducet, N., Le Traon, P. Y., and Reverdin, G.: Global high resolution mapping of ocean circulation from the combination of TOPEX/Poseidon and ERS-1/2, J. Geophys. Res., 105, 19477 19498, 2000.

Durack, P. J. and Wijffels, S. E.: Fifty-year trends in global ocean salinities and their relationship to broad-scale warming, J. Climate, 23, 4342-4362, 2010.

Fratantoni, D. M.: North Atlantic surface circulation during the 1990's observed with satellite-tracked drifters, J. Geophys. Res., 106, 22067-22093, 2001.

Freeland, H. J., Roemmich, D., Garzoli, S. L., Le Traon, P. Y., Ravichandran, M., Riser, S., Thierry, V., Wijffels, S., Belbeoch, M., Gould, J., Grant, F., Ignazewski, M., King, B., Klein, B., Mork, K. A., Owens, B., Pouliquen, S., Sterl, A., Suga, T., Suk, M.-S., Sutton, P., Troisi, A., Velez-Belchi, P. J., and Xu, J.: Argo - A Decade of Progress, Proceedings of OceanObs'09: Sustained Ocean Observations and Information for Society (Vol. 2), Venice, Italy, 21-25 September 2009, Hall, J., Harrison, D. E. and Stammer, D. (Eds.), ESA Publication WPP-306, 2010.

$\mathrm{Fu}$, L.-L.: Pattern and velocity of propagation of the global ocean eddy variability, J. Geophys. Res., 114, C11017, doi:10.1029/2009JC005349, 2009.

Fu, L.-L. and Chelton, D. B.: Large-scale ocean circulation, Satellite Altimetry and Earth Sciences: A Handbook for Techniques and Applications, in: Academic Press, edited by: Fu, L. L. and Cazenave, A., San Diego, 423, 133-16, 2001.

Fu, L.-L, Zlotnicki, V., and Chelton, D. B.: Satellite altimetry observing ocean variability from space, Oceanography, 1, 4, doi:10.5670/oceanog.1988.01, 1988.

Fu, L.-L., Chelton, D. B., Le Traon, P. Y., and Morrow, R.: Eddy dynamics from satellite altimetry, Oceanography, 23, 14-25, 2010.

Gordon, A. L. and Haxby, W. F.: Agulhas eddies invade the south Atlantic: evidence from GEOSAT altimeter and shipboard conductivity temperature-depth survey, J. Geophys. Res., 95, $3117-$ $3125,1990$.

Greenslade, D. J. M., Chelton, D., and Schlax, M.: The midlatitude resolution capability of sea level fields constructed from single and multiple satellite altimeter datasets, J. Atmos. Ocean. Tech., 14, 849-870, 1997.

Grodsky, S., Lumpkin, R., and Carton, J.: Spurious trends in global surface drifter currents, Geophys. Res. Lett., 38, L10606, doi:10.1029/2011GL047393, 2011.

Guinehut, S., Larnicol, G., and Le Traon, P. Y.: Design of an array of profiling floats in the North Atlantic from model simulations, J. Marine Syst., 35, 1-9, 2002.

Guinehut, S., Le Traon, P. Y., Larnicol, G., and Philipps, S.: Combining Argo and remote-sensing data to estimate the ocean threedimensional temperature fields - a first approach based on simulated observations, J. Marine Syst., 46, 85-98, 2004.
Guinehut, S., Le Traon, P. Y., and Larnicol, G.: What can we learn from Global Altimetry/Hydrography comparisons?, Geophys. Res. Lett., 33, L10604, doi:10.1029/2005GL025551, 2006.

Guinehut, S., Coatanoan, C., Dhomps, A. L., Le Traon, P. Y., and Larnicol, G.: On the use of satellite altimeter data in Argo quality control, J. Atmos. Ocean. Tech., 26, 395-402, 2009.

Guinehut, S., Dhomps, A.-L., Larnicol, G., and Le Traon, P.Y.: High resolution 3-D temperature and salinity fields derived from in situ and satellite observations, Ocean Sci., 8, 845-857, doi:10.5194/os-8-845-2012, 2012.

Hansen, J., Sato, M., Kharecha, P., and von Schuckmann, K.: Earth's energy imbalance and implications, Atmos. Chem. Phys., 11, 13421-13449, doi:10.5194/acp-11-13421-2011, 2011.

Hernandez, F., Le Traon, P. Y., and Morrow, R.: Mapping mesoscale variability of the Azores current using TOPEX/POSEIDON and ERS-1 altimetry, together with hydrographic and Lagrangian measurements, J. Geophys. Res., 100, 24995-25006, 1995.

Huang, H.-P., Kaplan, A., Curchitser, E. N., and Maximenko, N. A.: The degree of anisotropy for mid-ocean currents from satellite observations and an eddy-resolving model simulation, J. Geophys. Res., 112, C09005, doi:10.1029/2007JC004105, 2007.

International GODAE Steering Team: The Global Ocean Data Assimilation Experiment Strategic Plan, GODAE Report No. 6, December, 2000.

Jacobs, G. A. and Leben, R. R.: Loop Current eddy shedding estimated using GEOSAT altimeter data, Geophys. Res. Lett., 17, 2385-2388, 1990.

Jacobs, G. A., Barron, C. N., and Rhodes, R. C.: Mesoscale characteristics. J. Geophys. Res., 106, 19581-19595, 2001.

Johannessen, J. A., Le Traon, P.-Y., Robinson, I., Nittis, K., Bell, M. J., Pinardi, N., and Bahurel, P.: Marine Environment and Security for the European Area Toward Operational Oceanography, B. Am. Meteorol. Soc., 87, 1081-1090, doi:10.1175/BAMS-878-1081, 2006.

Kelly, K. A. and Gille, S. T.: Gulf stream surface transport and statistics at $69^{\circ} \mathrm{W}$ from the GEOSAT altimeter, J. Geophys. Res., 95, 3149-3161, 1990.

Koblinsky, C., Gaspar, P., and Lagerloef, G.: The Future of Spaceborne Altimetry - Oceans and Climate Change: A Long-Term Strategy, Joint Oceanographic Institutions, Inc., 85 pp., 1992.

Lapeyre, G. and Klein, P.: Dynamics of the Upper Oceanic Layers in Terms of Surface Quasigeostrophy Theory, J. Phys. Oceanogr., 36, 165-176, 2006.

Le Traon, P. Y.: Time scales of mesoscale variability and their relationship with spatial scales in the North Atlantic, J. Mar. Res., 49, 467-492, 1991.

Le Traon, P. Y. and Ogor, F.: ERS-1/2 orbit improvement using T/P: The $2 \mathrm{~cm}$ challenge, J. Geophys. Res., 103, 8045-8057, 1998.

Le Traon, P. Y. and Dibarboure, G.: Mesoscale mapping capabilities of multiple-satellite altimeter missions, J. Atmos. Ocean. Tech., 16, 1208-1223, 1999.

Le Traon, P.-Y. and Morrow, R.: Ocean currents and eddies, in: Satellite Altimetry and Earth Sciences: A Handbook for Techniques and Applications, Academic Press, edited by: Fu, L.-L. and Cazenave, A., San Diego, 171-210, 2001.

Le Traon, P.-Y. and Dibarboure, G.: Velocity mapping capabilities of present and future altimeter missions: The role of high frequency signals, J. Atmos. Ocean. Tech., 19, 2077-2088, 2002. 
Le Traon, P. Y., Rouquet, M. C., and Boissier, C.: Spatial scales of mesoscale variability in the North Atlantic as deduced from GEOSAT data, J. Geophys. Res., 95, 20267-20285, 1990.

Le Traon, P. Y., Gaspar, P., Bouyssel, F., and Makhmaraa, H.: Using Topex/Poseidon data to enhance ERS-1 data, J. Atmos. Ocean. Tech., 12, 161-170, 1995a.

Le Traon, P. Y., Gaspar, P., Ogor, F., and Dorandeu, J.: Satellites work in tandem to improve accuracy of data, EOS, Trans. AGU, 76, 385, 389, 1995b.

Le Traon, P. Y., Nadal, F., and Ducet, N.: An improved mapping method of multisatellite altimeter data, J. Atmos. Ocean. Tech., 15, 522-533, 1998.

Le Traon, P. Y., Dibarboure, G., and Ducet, N.: Use of a High-Resolution model to analyze the mapping capabilities of multiple-altimeter missions, J. Atmos. Ocean. Tech., 18, 12771288, 2001a.

Le Traon, P. Y., Rienecker, M., Smith, N., Bahurel, P., Bell, M., Hurlburt, H., and Dandin, P.: Operational oceanography and prediction - a GODAE perspective, in: Observing the Oceans in the 21st Century, edited by: Koblinsky, C. J. and Smith, N. R., http://archimer.ifremer.fr/doc/00090/20096/, 2001b.

Le Traon, P. Y., Klein, P., Hua, B. L., and Dibarboure, G.: Do altimeter data agree with interior or surface quasi-geostrophic theory?, J. Phys. Oceanogr., 38, 1137-1142, 2008.

Maximenko, N. A. and Niiler, P. P.: Mean surface circulation of the global ocean inferred from satellite altimeter and drifter data. In 15 years of Progress in Radar Altimetry, ESA Publication SP614, 2006.

Maximenko, N. A., Bang, B., and Sasaki, H.: Observational evidence of alternating zonal jets in the World Ocean, Geophys. Res. Lett., 32, L12607, doi:10.1029/2005GL022728, 2005.

Maximenko, N. A., Melnichenko, O. V., Niiler, P. P., and Sasaki, H.: Stationary mesoscale jet-like features in the ocean, Geophys. Res. Lett., 35, L08603, doi:10.1029/2008GL033267, 2008.

Mitchum, G. T.: Monitoring the stability of satellite altimeters with tide gauges, J. Atmos. Ocean. Tech., 15, 721-730, 1998.

Morrow, R. and Le Traon, P. Y.: Recent advances in observing mesoscale ocean dynamics with satellite altimetry, Adv. Space Res., 50, 1062-1076, 2012.

Morrow, R. A., Church, J. A., Coleman, R., Chelton, D. B., and White, N.: Eddy momentum flux and its contribution to the Southern Ocean momentum balance, Nature, 357, 482-484, 1992.

Morrow, R. F., Birol, D., Griffin, and Sudre, J.: Divergent pathways of anticyclonic and cyclonic eddies, Geophys. Res. Lett., 31, L24311, doi:10.1029/2004GL020974, 2004.

Oke, P. R., Balmaseda, M. A., Benkiran, M., Cummings, J. A., Fujii, Y., Guinehut, S., Larnicol, G., Le Traon, P. Y., Martin, M. J., and Dombrowsky, E.: Observing System Evaluations using GODAE systems, Oceanography, 22, 144-153, 2009.

Pascual, A., Faugere, Y., Larnicol, G., and Le Traon, P. Y.: Improved description of the ocean mesoscale variability by combining four satellite altimeters, Geophys. Res. Lett., 33, L02611, doi:10.1029/2005GL024633, 2006.

Pascual, A., Pujol, M. I., Larnicol, G., Le Traon, P. Y., and Rio, M. H.: Mesoscale Mapping Capabilities of Multi-satellite Altimeter Missions: First Results with Real Data in the Mediterranean Sea, J. Marine Syst., 65, 190-211, 2007.
Pascual, A., Boone, C., Larnicol, G., and Le Traon, P. Y.: On the quality of real-time altimeter gridded fields: comparison with in situ data, J. Atmos. Ocean. Tech., 26, 556-569, 2009.

Penduff, T., Juza, M., Brodeau, L., Smith, G. C., Barnier, B., Molines, J.-M., Treguier, A.-M., and Madec, G.: Impact of global ocean model resolution on sea-level variability with emphasis on interannual time scales, Ocean Sci., 6, 269-284, doi:10.5194/os6-269-2010, 2010.

Picaut, J. and Busalacchi, A. J.: Tropical Ocean Variability. Satellite Altimetry and Earth Sciences. A Handbook of Techniques and Applications, in: Academic Press, edited by: Fu, L.-L. and Cazenave, A., 217-236, 2001.

Qiu, B. and Chen, S.: Seasonal modulations in the eddy field of the South Pacific Ocean, J. Phys. Oceanogr., 34, 1515-1527, 2004.

Qiu, B. and Chen, S.: Eddy-mean flow interaction in the decadallymodulating Kuroshio Extension system, Deep-Sea Res. II, 57, 1098-1110, 2010.

Qiu, B., Kelly, K. A., and Joyce, T. M.: Mean flow and variability in the Kuroshio Extension from GEOSAT altimetry data, J. Geophys. Res., 96, 18491-18507, 1991.

Richman, J. G., Arbic, B. K., Shriver, J. F., Metzger, E. J., and Wallcraft, A. J.: Inferring dynamics from the wavenumber spectra of an eddying global ocean model with embedded tides, J. Geophys. Res., 117, C12012, doi:10.1029/2012JC008364, 2012.

Rio, M. H., Guinehut, S., and Larnicol, G.: New CNES-CLS09 global mean dynamic topography computed from the combination of GRACE data, altimetry, and in situ measurements, J. Geophys. Res., 116, C07018, doi:10.1029/2010JC006505, 2011.

Roemmich, D., Boebel, O., Desaubies, Y., Freeland, H., King, B., Le Traon, P. Y., Molinari, R., Owens, W. B., Riser, S., Send, U., Takeuchi, K., and Wijffels, W.: Argo, the global array of profiling floats. OceanObs99: International Conference on the Ocean Observing System for Climate, 18-22 October 1999, Saint-Raphael, France, 1999.

Roemmich, D., Gilson, J., Davis, R., Sutton, P., Wijffels, S., and Riser, S.: Decadal spinup of the South Pacific subtropical gyre, J. Phys. Oceanogr., 37, 162-173, 2007.

Roemmich D., Belbeoch, M., Belchi, P. J. V., Freeland, H., Gould, W. J., Grant, F., Ignaszewski, M., King, B., Klein, B., Mork, K. A., Owens, W. B., Pouliquen, S., Ravichandran, M., Riser, S., Sterl, A., Suga, T., Suk, M.-S., Sutton, P., Thierry, V., Le Traon, P.-Y., Wijffels, S., and Xu, J.: Argo: the challenge of continuing 10 years of progress, Oceanography, 22, 46-55, 2009.

Smith, N. and Lefebvre, M.: The Global Ocean Data Assimilation Experiment (GODAE), in: "Monitoring the oceans in the 2000s: an integrated approach", International Symposium, Biarritz, 1517 October 1997.

Stammer, D. and Böning, C. W.: Mesoscale variability in the Atlantic ocean from GEOSAT altimetry and Woce high resolution numerical modelling, J. Phys. Oceanogr., 22, 732-752, 1992.

Stammer, D., Tokmakian, R., Semtner, A., and Wunsch, C.: How well does a $1 / 4^{\circ}$ global ocean circulation model simulate large scale oceanic observations, J. Geophys. Res., 101, 25779-25811, 1996.

Tai, C. K.: The Resolving Power of a Single Exact-Repeat Altimetric Satellite or a Coordinated Constellation of Satellites, J. Atmos. Ocean. Tech., 21, 810-818, 2004.

Tai, C. K.: Aliasing of Sea Level Sampled by a Single Exact-Repeat Altimetric Satellite or a Coordinated Constellation of Satellites: 
Analytic Aliasing Formulas, J. Atmos. Ocean. Tech., 23, 252267, 2006

Tai, C.-T. and White, W. B.: Eddy variability in the Kuroshio extension as revealed by Geosat altimetry. Energy propagation away from the jet, Reynolds stress, and seasonal cycle, J. Phys. Oceanogr., 20, 1761-1777, 1990.

Thompson, K. R. and Demirov, E.: Skewness of sea level variability of the world's oceans, J. Geophys. Res., 111, C05005, doi:10.1029/2004JC002839, 2006.

Trenberth, K. E.: The ocean is warming, isn't it?, Nature, 465, 304 304, 2010.

Vage, K., Pickart, R. S., Thierry, V., Reverdin, G., Lee, C. M., Petrie, B., Agnew, T. A., Wong, A., and Ribergaard, M. H.: Surprising return of deep convection to the subpolar North Atlantic Ocean in winter 2007-2008, Nat. Geosci., 2, 67-72, 2009.

von Schuckmann, K. and Le Traon, P.-Y.: How well can we derive Global Ocean Indicators from Argo data?, Ocean Sci., 7, 783791, doi:10.5194/os-7-783-2011, 2011. von Schuckmann, K., Gaillard, F., and Le Traon, P. Y.: Global hydrographic variability patterns during 2003-2008, J. Geophys. Res., 114, C09007, doi:10.1029/2008JC005237, 2009.

Wilkin, J. L. and Morrow, R. A.: Eddy kinetic energy and momentum flux in the Southern Ocean: Comparison of a global eddyresolving model with altimeter, drifter, and current-meter data, J. Geophys. Res., 99, 7903-7916, 1994.

Wunsch, C.: Sampling characteristics of satellite orbits, J. Atmos. Ocean. Tech., 6, 891-907, 1989.

Wunsch, C.: Global problems and global observations, in: Academic, Ocean Circulation and Climate. Observing and Modelling the Global Ocean, edited by: Siedler, G., Church, J. and Gould, J., 47-80, San Diego, 2001.

$\mathrm{Xu}, \mathrm{Y}$. and Fu, L. L.: The effects of altimeter instrument noise on the estimation of the wavenumber spectrum of sea surface height, $\mathrm{J}$. Phys. Oceanogr., 42, 2229-2233, 2012.

Zlotnicki, V., Fu, L.-L., and Patzert, W.: Seasonal variability in a global sea level observed with GEOSAT altimetry, J. Geophys. Res., 94, 17959-179691989. 